\title{
Reduced Conditionals and Focus
}

\author{
Maribel Romero \\ University of Pennsylvania
}

\section{Introduction}

The term "Reduced Conditional" is coined by Schwarz $(1996,1998,2000)$ to designate a certain kind of ellipsis that may occur in the consequent of a Conditional in German, as illustrated in (1): (1a) is a Full Conditional (FC, henceforth) and (1b) is its Reduced Conditional (RC) counterpart.

(1) Reduced Conditionals in German:

a. Wenn ich wen besuche, dann besuche ich (immer) den Peter.

If I somebody visit then visit I always the Peter

"If I visit somebody, then I always visit Peter."

b. Wenn ich wen besuche, dann $\boldsymbol{\Delta}$ (immer) den Peter.

If I somebody visit then always the Peter

"If I visit somebody, then always Peter / it's Peter"."

(Schwarz 1998)

The following terminology will be used. The clause containing the ellipsis (dann immer den Peter "then $\Psi$ always Peter" in (1b)) is called ellipsis clause. The constituent --other than dann ("then"), immer ("always") and possibly other particles-- that remains expressed in the ellipsis clause is called the remnant (den Peter "the Peter"). The clause from which the elided information is retrieved will be referred to as antecedent clause (ich wen besuche "I visit someone"). Finally, the constituent in the antecedent clause that corresponds to the remnant in the ellipsis clause will be called antecedent (constituent) or correlate (wen "someone" in (1b)).

Schwarz $(1996,1998,2000)$ notes the following four important contrasts between a Reduced Conditional and its full counterpart. Interestingly, other ellipsis constructions like VP-Ellipsis do not exhibit these contrasts. ${ }^{2}$

(i) Restriction on possible types of correlates in Reduced Conditionals. Schwarz $(1998,2000)$ observes that switching the indefinite correlate in (1b) into a name -as in (2b) - renders the Reduced Conditional ungrammatical. The full-fledged version (2a) is fine. No such ban against names as correlates applies in VP-Ellipsis, as (3) shows.

a. Wenn ich den Karl besuche, dann besuche ich (immer) den Peter.

If I the Karl visit, then visit I always the Peter

"If I visit Karl, then I always visit Peter."

b. * Wenn ich den Karl besuche, dann $\boldsymbol{\Delta}$ (immer) den Peter.

If I the Karl visit, then always the Peter

"If I visit Karl, then always Peter."

(Schwarz 1998)

(3) Susan likes turnips, but Cecilia doesn't $\boldsymbol{\Delta}$. 
(ii) Presupposition effect. The RC in (4b) presupposes that Simone is a student. Similarly, Schwarz' RC in (5b) carries the odd presupposition that my glasses are something to read. They contrast with their full versions (4a)-(5a), which do not necessarily carry those presuppositions. This presupposition effect does not arise in VPEllipsis: (6) does not presuppose that Marcia is a student.

a. Wenn ich eine Studentin besuche, dann besuche ich immer Simone.

If I a student-FEM visit then visit I always Simone

"If I visit a student, then I always visit Simone."

b. Wenn ich eine Studentin besuche, dann $\boldsymbol{\Delta}$ immer Simone.

If I a student-FEM visit then always Simone

"If I visit a student, then always Simone."

(5) a. Wenn ich was zum Lesen mitnehme, dann nehme ich immer meine Brille mit.

If I something to read take then take I always my glasses

"If I take something to read, then I always take my glasses."

b. !! Wenn ich was zum Lesen mitnehme, dann $\boldsymbol{\Delta}$ immer meine Brille.

If I something to read take then always my glasses

"If I take something to read, then always my glasses."

(Schwarz 1998)

(6) a. Some student came, but Marcia didn't $\mathbf{\Delta}$.

b. Some student came, and Marcia did $\boldsymbol{\Delta}$ too.

(iii) Exhaustiveness effect. Schwarz $(1998,2000)$ notes that the RC (7b) is false if I visit someone other than Peter, whereas its full version (7a) may be true. This exhaustiveness effect of RC is not found in VP-Ellipsis, as witnessed in (8).

(7) a. Wenn ich wen besuche, dann besuche ich immer den Peter.

If I somebody visit, then visit I always the Peter

"If I visit somebody, then I always visit Peter."

b. Wenn ich wen besuche, dann $\boldsymbol{\Delta}$ immer den Peter.

If I somebody visit, then always the Peter

"If I visit somebody, then always Peter."

(Schwarz 1998)

(8) I visited everybody that Peter $\operatorname{did} \boldsymbol{\Delta}$.

a. "I visited everybody that Peter - and possibly others - visited."

(iv) Definiteness effect. As noted in Schwarz (1996), in RCs, indefinite NPs other than the correlate in the antecedent-clause are interpreted as definite expressions in the ellipsis clause. That is, the Full Conditional (9a) may be talking about two students (per day) ordering different things, e.g., the first one ordering a strong liquor and the second one ordering beer, as in scenario (10). The RC (9b), instead, talks about the same student in the antecedent and consequent of the conditional and it is false in scenario (10), where the first students do not order beer. No such restriction operates in VP-Ellipsis: two different monasteries may be involved in (11b). 
Reduced Conditionals:

a. Wenn ein Student was zum Trinken bestellt, dann bestellt ein Student Bier.

If a student something to drink orders, then orders a student beer

"If a student orders something to drink, then a student orders beer."

b. Wenn ein Student was zum Trinken bestellt, dann $\boldsymbol{\Delta}$ Bier.

If a student something to drink orders, then beer

"If a student orders something to drink, then beer."

(Schwarz 1996)

(10) Scenario: In day 1, student A orders cognac and student B orders (only) beer.

In day 2 , student $C$ orders rum and student $D$ orders (only) beer.

In day 3 , student $\mathrm{E}$ orders absinthe and student $\mathrm{F}$ orders (only) beer.

(11) VP-Ellipsis:

a. Greg visited a monastery, and Mathias visited a monastery, too.

b. Greg visited a monastery, and Mathias did $\boldsymbol{\Delta}$, too.

In order to derive these contrasts between Reduced and Full Conditionals, Schwarz' detailed study proposes different Logical Forms for a RC and its full counterpart. However, this analysis -in terms of co-indexing situations variables in a $\mathrm{RC}$ - does not seem applicable to other elliptical constructions and, hence, singles out Reduced Conditionals as a highly idiosyncratic type of ellipsis. The goal of the present paper is to advance an alternative analysis to Schwarz' approach that makes Reduced Conditionals comparable to other ellipsis phenomena. I propose that a RC and its full counterpart have the same basic LF and that their differences derive entirely from the felicity conditions and projection possibilities of Focus. The four characteristics described above obtain as a by-product of the interaction of Focus and the semantics of Conditionals in general. This avenue is in consonance with the Focus-based approach to ellipsis phenomena that is gaining terrain these days (for VP-Ellipsis, see Rooth 1992b, and also Fox 1999, Tancredi 1992, Tomioka 1995, among many others; for Sluicing, see Romero 1998; for Gapping, see Sag 1980, Johnson 1996.)

The rest of this paper is organized as follows. In section 2, Schwarz' (1998, 2000) analysis will be briefly sketched. Section 3 contains the first part of the new proposal: the characteristics (i)-(iv) of Reduced Conditionals will be derived, as well as some further cases that Schwarz $(1998,2000)$ does not account for. Section 4 presents the second part of the proposal, which explains why Full Conditionals do not give rise to the same effects. Section 5 concludes this paper.

\section{Schwarz' (1998, 2000) analysis}

According to Schwarz' (1998, 2000), Full Conditionals introduce an indefinite situation variable with a new index, whereas Reduced Conditionals introduce a definite situation variable with the same index as the situation in the antecedent clause (cf. Heim 1982 for individual variables). This is summarized in his schema (12). The adverb of quantification quantifies over minimal events or situations, as characterized in (13) (see Kratzer 1989, Zucchi 1989, Portner 1992; for an elaboration of (13), see Kratzer 1998). 
(12) For any two situation variables $\mathrm{i}, \mathrm{j}$, a Reduced Conditional has the LF in (ii) if its full counterpart has the LF in (i):

(i) $\quad$ always $_{\mathrm{i}} \ldots[\mathrm{s} \ldots]_{\mathrm{i}} \exists_{\mathrm{j}} \ldots[\mathrm{s} \ldots]_{\mathrm{j}}$

(Schwarz 1998, 2000)

(ii) always $_{\mathrm{i}} \ldots[\mathrm{s} \ldots]_{\mathrm{i}} \exists \ldots[\mathrm{s} \ldots]_{\mathrm{i}}$

(13) A situation e is a minimal event that makes a proposition $p$ true only if $p$ is true in $\mathrm{e}$ and $\mathrm{e}$ has no proper part in which $\mathrm{p}$ is true.

These assumptions derive the restriction on possible correlates as follows. The Full Conditional (14a) is perfectly grammatical and has the congruent truth conditions in (15). However, in the Reduced Conditional, the minimal event described in the consequent of the Conditional is forced to be the same as the minimal event introduced in the antecedent. This requirement leads to the deviant truth conditions in (16). According to (16), every minimal event of me visiting Karl is a minimal event of me visiting Peter. Hence, assuming that Karl and Peter are not the same person, the RC (14b) is false whenever felicitous (i.e., whenever there is a minimal event of me visiting Karl to begin with). This, Schwarz argues, is the source of its ungrammaticality.

(14) a. Wenn ich den Karl besuche, dann besuche ich (immer) den Peter. "If I visit Karl, then I always visit Peter."

b. * Wenn ich den Karl besuche, dann $\boldsymbol{\Delta}$ (immer) den Peter. "If I visit Karl, then always Peter."

(Schwarz 1998)

(15) Full Conditional (14a): "If I visit Karl, I always visit Peter."

"For every minimal event e that makes the proposition [[I visit Karl]] true, there is an event e' such that e' matches (i.e., is related in a particular way to) e and $\mathbf{e}^{\prime}$ is a minimal event that makes the proposition [[I visit Peter $]$ true".

(16) Reduced (14b): "If I visit Karl, then always Peter."

\# "For every minimal event e that makes the proposition [[I visit Karl $]]$ true, e matches $\mathrm{e}$ and $\mathbf{e}$ is a minimal event that makes the proposition [[I visit Peter $]]$ true".

The anaphoricity of the consequent's situation variable is responsible for the presupposition effect, too. The derived truth conditions of the Full Conditional (17a) and of its reduced counterpart (17b) are spelled out in (18) and (19) respectively. Roughly, (19) says that every minimal event of me taking something to read is a minimal event of me taking my glasses. Given the definition of minimal event above, my glasses must then be something to read.

(17) a. Wenn ich was zum Lesen mitnehme, dann nehme ich immer meine Brille mit.

If I something to read take then take I always my glasses

"If I take something to read, then I always take my glasses."

b. !! Wenn ich was zum Lesen mitnehme, dann $\boldsymbol{\Delta}$ immer meine Brille.

If I something to read take then always my glasses

"If I take something to read, then always my glasses." 
(18) Full Cond. (17a): "If I take something to read, I always take my glasses." "For every minimal event e that makes the proposition [[I take something to read]] true, there is an event e' such that e' matches (i.e., is related in a particular way to) e and $\mathbf{e}$ ' is a minimal event that makes the proposition [[I take my glasses]] true".

(19) Red. Cond. (17b): "If I take something to read, then always my glasses." !! "For every minimal event e that makes the proposition [[I take something to read $]$ true, e matches e and e is a minimal event that makes the proposition [[I take my glasses]] true".

The exhaustiveness effect of the RC (20b) follows in the same fashion. The truth conditions in (22) dictate that the RC (20b) is true only if I always visit Peter and nobody else. This exclusivity is not required by the truth conditions (21) of the full version (20a).

a. Wenn ich wen besuche, dann besuche ich immer den Peter.

If I somebody visit, then visit I always the Peter

"If I visit somebody, then I always visit Peter (and maybe someone else)."

b. Wenn ich wen besuche, dann $\boldsymbol{\Delta}$ immer den Peter.

If I somebody visit, then always the Peter

"If I visit somebody, then always Peter ."

(21) Full Conditional (20a): "If I visit somebody, I always visit Peter."

"For every minimal event e that makes the proposition [[I visit somebody]] true, there is an event e' such that e' matches (i.e., is related in a particular way to) e and $\mathbf{e}$ ' is a minimal event that makes the proposition [[I visit Peter ]] true".

(22) Red. Cond. (20b): "If I visit somebody, then always Peter."

"For every minimal event e that makes the proposition [[I visit somebody]] true, e matches $\mathrm{e}$ and $\mathbf{e}$ is a minimal event that makes the proposition [[I visit Peter $]]$ true".

Finally, the definiteness effect on non-correlate indefinites can be derived from the coindexation of the two minimal situation variables in the RC (23b), too. ${ }^{3}$ That gives us the truth conditions in (25): since the two minimal events are the same, the students in them must be the same as well. No such effect arises with the truth conditions (24) of the Full Conditional (23a).

a. Wenn ein Student was zum Trinken bestellt, dann bestellt ein Student Bier.

If a student something to drink orders, then orders a student beer

"If a student orders something to drink, then a student orders beer."

b. Wenn ein Student was zum Trinken bestellt, dann $\boldsymbol{\Delta}$ Bier.

If a student something to drink orders, then beer

"If a student orders something to drink, then beer."

(Schwarz 1996) 
(24) Full Conditional (23a): "If a student orders something to drink, then a student always orders beer."

"For every minimal event e that makes the proposition [[a student orders something to drink]] true, there is an event e' such that e' matches (i.e., is related in a particular way to) $\mathrm{e}$ and $\mathbf{e}^{\prime}$ is a minimal event that makes the proposition [ $[a$ student orders beer]] true".

(25) Red. Cond. (23b): "If a student orders something to drink, then always beer."

"For every minimal event $\mathrm{e}$ that makes the proposition [[a student orders something to drink]] true, e matches e and e is a minimal event that makes the proposition [[a student orders beer]] true".

We have seen how Schwarz' $(1998,2000)$ LF coindexing approach can account for the contrasts (i)-(iv) between RCs and their full counterparts. Still, it wrongly excludes the following grammatical data:

(a) Data A: As noted by Schwarz himself, adding auch ("also") to the RC (14b) makes the restriction on possible correlates disappear:

(26) Wenn ich den Karl besuche, dann $\boldsymbol{\Delta}$ (immer) auch den Peter.

If I the Karl visit, then always also the Peter

"If I visit Karl, then always also Peter."

(Schwarz 2000)

(b) Data B: Schwarz' $(1998,2000)$ truth conditions for RC wrongly predict (27) to be necessarily false (when felicitous), as spelled out under (28). That should give it the say status as the ungrammatical (14b). (In the case of allein "alone", I assume, following Kratzer (1989:643ff.), that negative sentences can only be true in situations large enough to test that the relevant property does not hold for any of the contextually salient candidates -in this case, for any of my potential movie companions.)

(27) Wenn ich ins Kino gehe, dann $\boldsymbol{\Delta}$ immer mit Simone / allein.

If I to movies go, then $\boldsymbol{\Delta}$ always with Simone / alone

"If I go to the movies, then always with Simone / alone."

(28) "For every minimal event e that makes the proposition [[I got to the movies]] true, e matches e and $\mathbf{e}$ is a minimal event that makes the proposition [ [ I go to the movies with Simone / alone]] true".

(c) Data C: Again, Schwarz (1998, 2000) wrongly predicts (29) to be necessarily false (when felicitous) and, hence, as deviant as the ungrammatical (14b). Note, by the way, that the sentence deteriorates if we remove the stress from UND "AND".

$\boldsymbol{V} /$ ?Wenn jemand ein Bier bestellt, dann $\boldsymbol{\Delta}$ immer ein Bier UND einen Ouzo.

If somebody a beer orders, then $\boldsymbol{\Delta}$ always a beer AND an ouzo

"If somebody orders a beer, then always a beer AND and ouzo."

In the next sections, I will develop an alternative account to Schwarz' that obtains the differences in (i)-(iv) without stipulating different LFs and that, furthermore, covers the data A-C. 


\section{Part 1 of the proposal: exhaustive Focus in Reduced Conditionals}

This section presents the main part of the new proposal, aimed to derive the characteristics (i)-(iv) and the data A-B-C for Reduced Conditionals. Two main points will be made.

The first point is that, in order to derive the appropriate, congruent meaning for the sentences in the data A through $\mathrm{C}$, we need weaker truth conditions for RCs. Instead of Schwarz' $(1998,2000)$ schema in (30), the semantic contrast between RCs and their full counterparts should be characterized as in (31). (The truth conditions in (31b) amount to von Fintel's (1994:64) proposal for adverbs of quantification with Focus structures; they also correspond to Schwarz' (1996) early version, abandoned in his later work.)

(30) Schwarz' (1998, 2000):

a. Full Conditional: "Every minimal event that makes [[S1]] true is matched by a minimal event e' that makes [[S2]] true."

b. Reduced Conditional: "Every minimal event e that makes [[S1]] true is a minimal event e that makes [[S2]] true."

(31) New schema (basically as in Schwarz 1996; cf. von Fintel 1994):

a. Full Conditional: "Every minimal event e that makes [[S1]] true can be extended to an event e' that makes [[S2]] true."

b. Reduced Conditional: : "Every minimal event e that makes [[S1]] true can be extended to a minimal event e' that makes [[S2]] true."

The second point is concerned with how to derive the difference between the truth conditions in (31a) and (31b), i.e., how to derive the minimality of the second event in (31b). I will propose that this difference does not stem from two different LFs, but from the presence of "free" Focus on the remnant of the RC. This Focus introduces an exhaustivity implicature that is responsible for the minimality effect of the second situation in (31b), from which the characteristics (i)-(iv) and the data A-C will follow.

\subsection{Focus and exhaustivity implicature}

Besides the proposition that they ordinarily express, sentences with focused material introduce a set of Focus alternative propositions (Rooth 1985, 1992a): the set of propositions resulting from replacing the denotation of the focused element(s) with another object of the same type. The recursive definition of the set of Focus alternatives or Focus semantic value-is spelled out under (32) and exemplified under (33).

(32) Recursive definition of Focus semantic value [[.] $]^{\mathrm{F}, \mathrm{g}}$, for any assignment $\mathrm{g}$ :

a. If $\alpha$ is a terminal node, then $[[\alpha]]^{\mathrm{F}, g}=\left\{[[\alpha]]^{\mathrm{F}, \mathrm{g}}\right\}$.

(Rooth 1985)

b. If $\alpha$ is a non-branching node with single daughter $\beta$, then $[[\alpha]]^{\mathrm{F}, \mathrm{g}}=[[\beta]]^{\mathrm{F}, \mathrm{g}}$.

c. If $\alpha$ is a branching node with daughters $\beta$ and $F$ (Focus feature), then $[[\alpha]]^{\mathrm{F}, \mathrm{g}}=$ $D_{\sigma}$, where $\sigma$ is the type of $[[\beta]]^{g}$.

d. If $\alpha$ is a branching node with daughters $\beta$ and $\gamma$ (order irrelevant), and there are types $\sigma$ and $\tau$ such that $[[\beta]]^{\mathrm{g}} \in \mathrm{D}_{<\sigma, \tau>}$ and $[[\gamma]]^{\mathrm{g}} \in \mathrm{D}_{\sigma}$, then $[[\alpha]]^{\mathrm{F}, \mathrm{g}}=$ $\left\{\mathrm{x} \in \mathrm{D}_{\tau}: \exists \mathrm{y} \exists \mathrm{z}\left[\mathrm{y} \in[[\beta]]^{\mathrm{F}, \mathrm{g}} \& \mathrm{z} \in[[\gamma]]^{\mathrm{F}, \mathrm{g}} \& \mathrm{x}=\mathrm{y}(\mathrm{z})\right]\right\}$ 
John introduced Bill to SUE.

a. Proposition expressed: [[John introduced Bill to SUE] $]^{\mathrm{g}}=$ "that John introduced Bill to Sue".

b. Set of Focus alternatives: [[John introduced Bill to SUE] $]^{\mathrm{F}, \mathrm{g}}=\left\{\mathrm{p}: \exists \mathrm{x}_{\mathrm{e}}[\mathrm{p}=\right.$ "that J. introduced Bill to $\left.\mathrm{x} "]\right\}$ E.g.: \{"that John introduced Bill to Sue", "that John introduced Bill to Miranda", "that John introduced Bill to Annelise"\}

Sentences containing focused material must obey some felicity conditions. In the case of question/answer pairs, we have a "free" Focus that requires that there be a salient question denotation (in Hamblin (1973) / Karttunen's (1977) style) that is a subset of the Focus semantic value of the sentence with the Focus (Rooth 1992a). This is exemplified in (34)-(35). Note that the question denotation does not have to be directly expressed by an interrogative sentence; it suffices to infer it from the surrounding discourse (or to accommodate it), as in (36).

(34) Q: Who did John introduce Bill to?

A: John introduced Bill to SUE.

a. For any situation or world s: $[[(34 \mathrm{Q})]]^{\mathrm{g}}(\mathrm{s})=\left\{\mathrm{p}: \exists \mathrm{x}_{\mathrm{e}}[\mathrm{p}=\right.$ "that John introduced Bill to $\mathrm{x}$ "] $\}$

E.g.: \{"that John introduced Bill to Sue", "that John introduced Bill to Miranda", "that John introduced Bill to Annelise"\}

b. $[[(34 \mathrm{~A})]]^{\mathrm{F}, \mathrm{g}}=\left\{\mathrm{p}: \exists \mathrm{x}_{\mathrm{e}}[\mathrm{p}=\right.$ "that John introduced Bill to $\mathrm{x}$ " $\left.]\right\}=(33 \mathrm{~b})$

c. $(35 a) \subseteq(35 b)$

(36) A: John introduced Bill to somebody.

B: John introduced Bill to SUE.

"Free" Focus introduces an exhaustivity implicature in the following way. Once the sentence with Focus is understood as the answer to a question, we assume that the utterer is competent to answer it and that s/he follows the Gricean conversational maxims. Furthermore, we assume that all the alternative propositions in the question denotation and their conjunctions are relevant to the subject of the conversation. ${ }^{4}$ Adding the Maxim of Quantity (37) to that, the exhaustivity implicature follows: given that the speaker uttered (34B) instead of expressing any stronger (conjoined) relevant proposition, $\mathrm{s} /$ he must (correctly) believe that no such stronger proposition is true. Hence the negative implicatures in (38a). (38a) plus [[(34A)]] yield the exhaustivity implicature in (38b). ${ }^{5}$

(37) Maxim of Quantity: Be as informative as possible.

(38) a. Negative implicatures:

"It is not the case that John introduced Bill to Sue and Miranda", "it is not the case that John introduced Bill to Sue and Annelise", "it is not the case that John introduced Bill to Sue, Miranda and Annelise".

b. Exhaustivity implicature: "John introduced Bill to Sue and to nobody else (relevant in the question)." 


\subsection{New proposal}

Let us go back to Reduced Conditionals. I propose that the LF of a Reduced Conditional is identical -except for Focus marking-- to the LF of its full counterpart. Both follow the interpretive schema in (39), which can be informally paraphrased as in (42). ${ }^{6}$ The special behavior of Reduced Conditionals is entirely due to the presence of Focus stress on the remnant material ((43)). This Focus is comparable to the free Focus in question/answer pairs and, as such, induces an exhaustivity implicature. ${ }^{7}$ In the next subsection, we will see how the characteristics (i)-(iv) result from the interaction of this implicature with the general semantics for Conditionals.

$\left[\left[\mathrm{ADV}_{7}[\text { if S1] S2 ] }]^{\mathrm{g}}=\right.\right.$ $\left\{\mathrm{s}:<\min \left([[\mathrm{S} 1]] \cap \mathrm{g}(7) \cap \mathrm{S}\left(\mathrm{w}_{\mathrm{s}}\right)\right),\left\{\mathrm{s}^{\prime}: \exists \mathrm{s}^{\prime \prime}\left(\mathrm{s}^{\prime \prime} \geq \mathrm{s} \prime \& \mathrm{~s} " \in[[\mathrm{S} 2]]\right)\right\}>\in[[\mathrm{ADV}]]\right\}$

(40) For any set of situations $S$, the set of minimal situations in $S$, $\min (S)=\left\{s \in S: \forall s^{\prime} \in S\left(s^{\prime} \geq s^{\prime} \rightarrow s^{\prime}=s^{\prime}\right)\right\}$

(41) For any world w, the set of situations that are part of that world, $\mathrm{S}(\mathrm{w})=\{\mathrm{s}: \mathrm{w} \geq \mathrm{s}\}$

(42) Semantic schema for Full and Reduced Conditionals:

"Every (contextually relevant) minimal event e that makes the proposition [[S1]] true can be extended to an event e' that makes the proposition [[S2]] true."

(43) The remnant in a Reduced Conditional bears Focus stress (free Focus).

\subsection{Characteristics (i)-(iv)}

Characteristic (i) -restriction on possible correlates - results from the fact that the exhaustivity implicature is inconsistent with the predicted truth conditions in (44). (44) makes the original sentence (2b) necessarily false (if felicitous at all): if I visit Karl in an event e, then necessarily I visit Karl in any extension e' of e; hence, e' cannot belong (to any subset of) the proposition "I do not visit Karl". Such deviant truth conditions make the original sentence $(2 b)$ unacceptable.

Reduced Conditional (2b): * "If I visit Karl, then Peter."

\# "Every minimal event e that makes the proposition [[I visit Karl]] true can be extended to an event e' that makes the proposition "I visit Peter and I do not visit Karl and I do not visit Pat" true."

Let us turn to characteristic (ii), the presupposition effect. Recall that the RC (4b) -repeated in its English translation under (45)-presupposes that Simone is a student. This is how that presupposition obtains. For the Focus on the ellipsis clause to be felicitous, its clause's Focus semantic value has to be a superset of a question denoted by or inferred from the antecedent clause, i.e., from the clause from which we retrieve the elided information (cf. Rooth 1992b). Take such question denotation to be "which student 
I visit", inferred from I visit a student. Hence, the Focus semantic value of $I$ visit SIMONE must include a proposition for at least every student. Once we compute the negative and exhaustivity implicatures, we obtain the proposition "I visit Simone and nobody else out of a set containing at least all the students". Now we are ready to read the truth conditions under (45). We see that, unless Simone is a student, the sentence will be necessarily false when felicitous. Hence, the only way to obtain congruent truth conditions is to assume that Simone is a student.

Reduced Conditional (5b): "If I visit a student, then always Simone." "Every minimal event e that makes the proposition [[I visit a student ]] true can be extended to an event e' that makes the proposition "I visit Simone and nobody other than her (out of a set containing at least all the students)" true."

As for the example (7b) illustrating the exhaustiveness effect --characteristic (iii)-, we obtain the truth conditions under (46). (46) says that every minimal event of me visiting somebody can be extended to an event e' that makes the propositions "I visit Peter" , "I do not visit Karl", ... and "I do not visit Pat" true. (Again, there should be a proposition for --at least-- everybody relevant to the question inferred from I visit somebody.) Recall that, for an event to make the proposition denoted by a negative sentence true, the event has to be large enough to test that the state or action expressed in the sentence did not occur (cf. Kratzer 1989:646). For example, the extended event e' in (46) would have to include, among other things, me, Karl and all the relations I bear to Karl, among which visiting is not included. Hence, (46) says that every event e of me visiting somebody is such that it can be extended to an event e' of me visiting Peter and it cannot be extended to any event e" of me visiting Karl or Pat (or anybody else relevant). Exhaustiveness follows: I only visit Peter.

Reduced Conditional (7b): "If I visit somebody, then Peter."

"Every minimal event e that makes the proposition [[I visit somebody]] true can be extended to an event e' that makes the proposition "I visit Peter and I do not visit Karl and I do not visit Pat" true."

Finally, the truth conditions that give rise to characteristic (iv) --definiteness effect-are exemplified under (47). Following the same reasoning about negative sentences as above, events of students ordering something can be extended to events of students ordering beer, but not to events of students ordering margaritas or students ordering lattes (or other relevant drinks). Hence, the student introduced in the antecedent of the conditional must order beer too. This derives the impression of definiteness.

Reduced Conditional (9b): "If a student orders something to drink, then beer."

"Every minimal event e that makes the proposition [[a student orders something]] true can be extended to an event e' that makes the proposition "a student orders beer and it is not the case that a student orders a margarita and it is not the case that a student orders a latte" true." 
In sum, the four characteristics arise from the interaction between the general semantics for Conditionals and the exhaustivity implicature. Note that an important ingredient to obtain these results is that the Focus in the ellipsis clause is understood as a "free" Focus answering the question implied by the protasis of the Conditional. If this Focus is, instead, understood as "free" Focus answering some other question in the discourse (as in (48)) or as contrastive Focus with respect a previous sentence (as in (49)), my analysis does not expect the aforementioned characteristics to arise. The expectation is borne out: (48) and (49) are grammatical and, hence, they do not show the restriction on possible correlates and/or the presupposition effect.

Q: Welchen Verwandten besuchst du sonntags?

"Which relative do you visit on Sundays?"

A: Wenn ich samstags den Karl / einen Freund in Krankenhaus besuche, dann immer meine Schwester Claudi.

"If I visit Karl / a friend(-masc.) at hospital on Saturday, then always my sister Claudi."

(49) Wenn ich nicht viel Zeit zum Kochen habe, dann lade ich meinen Bruder ein.

Wenn ich genug Zeit habe, dann $\boldsymbol{\Delta}$ meinen Vater $\boldsymbol{\Delta}$.

"If I don't have much time to cook, then I invited my brother. If I have enough time, then my father."

\subsection{Further cases}

Let us start with case B, exemplified again under (50). The characteristics that this case displays are summarized in (51). It has a reading under which is does not show exhaustiveness effect: (5) is compatible with me going always to the movies with Simone plus a random person. It does show definiteness effect, though: (52) is false if there is a student that goes to the movies without Simone (/ with somebody), even if there is a second student that goes to the movies with her (/ alone).

(50) Wenn ich ins Kino gehe, dann $\boldsymbol{\Delta}$ immer mit Simone / allein. If I to movies go, then $\boldsymbol{\Delta}$ always with Simone / alone "If I go to the movies, then always with Simone / alone."

(51) Characteristics:

i. Restriction on correlates: N/A.

ii. Presupposition effect: N/A.

iii. Exhaustiveness effect: No.

iv. Definiteness effect. Yes.

(52) Wenn ein Student ins Kino geht, dann $\boldsymbol{\Delta}$ immer mit Simone / allein.

If a student to movies goes, then $\boldsymbol{\Delta}$ always with Simone / alone "If a student goes to the movies, then always with Simone / alone." 
I propose that we have exhaustive, "free" Focus on the entire adjunct [mit Simone $]_{\mathrm{F}} /[\text { allein }]_{\mathrm{F}}$. (The relevant question denotation would be "Under which circumstances/conditions do you go to the movies?", inferred from the antecedent clause plus some accommodated information.) A sample set of Focus alternatives for mit Simone is given under (53). ${ }^{8}$ The resulting Focus semantic value of the ellipsis clause in (52) is spelled out under (54).

$$
\begin{aligned}
& \left.\left[[\text { [mit Simone }]_{F}\right]\right]^{\mathrm{F}, \mathrm{g}}= \\
& \{\text { "accompanied by Simone and possibly others", } \\
& \text { "alone", } \\
& \text { "accompanied by Claudi only", } \\
& \text { "accompanied by Claudi and others but not by Simone" }
\end{aligned}
$$

[[ A stentgos to the [with Simone $\left.\left.]_{F}\right]\right]^{\mathrm{F}, \mathrm{g}}=$

\{ "a student goes to the movies accompanied by Simone and possibly others",

"a student goes to the movies alone",

"a student goes to the movies accompanied by Claudi only",

"a student goes to the movies with Claudi and others but not with Simone"\}

Now we are ready to compute the truth conditions of (52). This is done in (55). We can see that the exhaustivity implicature affects the alternatives in (53), not the set of alternative individuals that a student may go with. That is why having other people's company besides Simone's is compatible with the sentence. As for the definiteness effect, it follows exactly as in the previous example (9b)/(47): a minimal event of a student going to the movies can be extended to an event e' of a student going with Simone, but

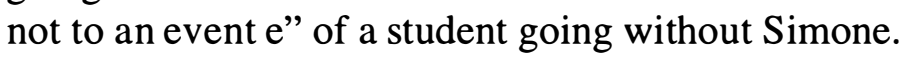

(55) RC (52): "If a student goes to the movies, then always with Simone".

"Every minimal event e that makes the proposition [[a student goes to the movies]] true can be extended to an event e' that makes the proposition "a student goes to the movies with Simone (and possibly others) and, for all other alternatives $\mathrm{p}$ in (54), $\neg$ p" true."

The next case that we will examine is case A, the case of auch "also". The original example is repeated under (56). We observe that this case does not display characteristics (i) and (iii). As for characteristics (iv), the judgement varies with the examples: we have a definiteness effect in (56) -the same person, the person picked in the protasis, must order both beer and ouzo - but not in (58) -the beverages ordered by Klaus and Hans may be different.

(56) Wenn jemand ein Bier bestellt, dann $\boldsymbol{\Delta}$ immer auch einen Ouzo.

If somebody a beer orders, then always also an ouzo

"If somebody orders a beer, then always also an ouzo."

(57) Characteristics:

i. Restriction on correlates: No.

ii. Presupposition effect: N/A. 
iii. Exhaustiveness effect: No. Possibly, that person could order beer, ouzo and something else.

iv. Definiteness effect. Yes in (56). Not in (58).

(58) Wenn der Klaus was zum Trinken bestellt, dann $\boldsymbol{\Delta}$ immer auch der Hans. If the Klaus something to drink orders, then always also the Hans "If Klaus orders something to drink, then always also Hans."

My proposal for this case follows the one I put forward for case B. I propose that we have "free" Focus on the entire phrase auch der Hans "also Hans". That gives us the sample set of (non-overlapping) alternatives in (59) and the Focus semantic value in (60). ${ }^{9}$ The resulting truth conditions are spelled out in (61).

[[ [auch der Hans $\left.\left.]_{F}\right]\right]^{\mathrm{F}, \mathrm{g}}=$

$\{$ "Klaus and Hans and possibly others",

"Klaus and nobody else",

"Klaus and Birgit and nobody else",

"Klaus and Birgit and others but not Hans" \}

[[ [Also Hans] $\left.]_{F}\right]^{\mathrm{F}, \mathrm{g}}=$

["Klaus, Hans and possibly others order something to drink",

"Klaus and nobody else orders something to drink",

"Klaus, Birgit and nobody else orders something to drink",

"Klaus, Birgit and others but not Hans order something to drink" \}

(61) RC (58): "If Klaus orders something to drink, then always also Hans."

"Every minimal event e that makes the proposition [[Klaus orders something to drink]] true can be extended to an event e' that makes the proposition "Klaus, Hans and possibly others order something to drink and, for all other alternatives $\mathrm{p}$ in (60), $\neg$ p" true."

The truth conditions in (61) are perfectly congruent. Hence, the prohibition against names as remnants does not obtain here. The exhaustivity implicature holds among the alternatives in (59), not among the set of alternative individuals that may order besides Klaus. That means that the exhaustiveness effect is dispensed with, too. Finally, the definiteness effect that we found in case B (example (52)) and in example (56) of case A is undone in (58) because the plural denoting Subject scopes over the indefinite. That is, the proposition "that Klaus and Hans (and possibly others) order something to drink" yields truth is a situation where Klaus and Hans order different things. As the reader can verify, nothing in the truth conditions in (61) forces them to order the same thing.

Finally, let us address the last problematic case for Schwarz' $(1998,2000)$ account: case C, the case of stressed UND "AND". The example is repeated under (62) and its characteristics are summarized under (63). No exhaustiveness effect is observed (possibly, the orderer could order beer, ouzo and something else), whereas the definiteness effect still holds ((62) is false is the person picked by the protasis does not order a beer and an ouzo). 
(62)

$\boldsymbol{V} /$ ? Wenn jemand ein Bier bestellt, dann $\boldsymbol{\Delta}$ immer ein Bier UND einen Ouzo. If somebody a beer orders, then $\boldsymbol{\Delta}$ always a beer AND an ouzo "If somebody orders a beer, then always a beer AND an ouzo."

Characteristics:

i. Restriction on correlates: N/A.

ii. Presupposition effect: N/A.

iii. Exhaustiveness effect: No.

iv. Definiteness effect. Yes.

This time, the pitch accent marks a narrow Focus on the conjunction itself. A set of alternatives for UND "AND" in this case is suggested under (64). We obtain the Focus semantic value in (65) for the ellipsis clause. (The question denotation that (65) has to match would be "whether somebody orders beer together with or without ouzo"; this question is inferred from the antecedent clause plus some accommodated information or, possibly, from the previous discourse.) From the resulting truth conditions in (66), the definiteness effect and the lack of exhaustiveness effect follow. ${ }^{10}$

(65) Corresponding set of Focus alternatives for the clause:

\{ "somebody orders beer and ouzo", "somebody orders beer and no ouzo" \}

(66) RC (62): "If somebody orders a beer, then always a beer AND an ouzo."

"Every minimal event e that makes the proposition [[somebody orders beer]] true can be extended to an event e' that makes the proposition "somebody orders beer and ouzo, and, for all other $p$ in $(65), \neg p$ " true."

In conclusion, in this section 3 we have seen that the characteristics (i)-(iv) of Reduced Conditionals can be derived from the regular semantics of Full Conditionals plus exhaustive, "free" Focus. Hence, we do not need to stipulate two differently indexed LFs for Reduced and Full Conditionals. Furthermore, the data A-C that posed a problem for Schwarz' $(1998,2000)$ approach are accounted for as well.

\section{Part 2 of the proposal: Accommodation and Focus projection in Full Conditionals}

My analysis so far completely relies on the semantics of Focus and Conditionals. Unless something else is said, the analysis predicts that the same effects will arise whenever we have the same intonational contour, regardless of whether we have a Reduced Conditional or a Full conditional.

This expectation is to some extent born out. If we place Focus stress on Peter in Schwarz' example (2a), the result is judged odd by many speakers unless we add auch ("too"). That is, to some degree, we obtain the restriction on possible correlates for Full Conditionals with Focus. However, example (5a) -repeated here as (67a)- is impleccable with Focus stress and without auch, contrary to the reduced counterpart (67b). Why? 
(67) a. Wenn ich was zum Lesen mitnehme, dann nehme ich immer meine BRILLE mit.

If I something to read take, then take I always my GLASSES

"If I take something to read, then I always take my GLASSES."

b. !! Wenn ich was zum Lesen mitnehme, dann $\boldsymbol{\Delta}$ immer meine BRILLE.

If I something to read take, then always my GLASSES

"If I take something to read, then always my GLASSES."

Here is where ellipsis per se plays an important role. There are two crucial differences between ellipsis and deaccenting (or non-accenting). The first one -I would like to suggest-is the way Focus projects: Focus can project through overt nonaccented material (as in (68) and (69A)) but not through elided material (as the oddness of (69A') suggests). Presumably, this is so because F-marked constituents cannot be deleted (see also Merchant 1999).

(68) John drove Mary's red convertible. What did he drive before that?

A: He drove [ her BLUE convertible $]_{F}$

(Schwarzschild 1997)

(69) I just talked to Bill's father. Who should I talk to next?
A: [PETER's father $]_{F}$
$\mathrm{A}^{\prime}:$ \# [PETER's $\left.\boldsymbol{\Delta}\right]_{\mathrm{F}}$
(A. Williams p.c.)

The second difference relates to the ease of accommodation of the Focus set of alternatives. In a full sentence with some Focus, the set of alternatives can be fully accommodated, at some cost ((70)); in an elliptical construction, it cannot ((71)).

(70) By the way, Gina saw MIRANDA $F$ in the supermarket.

Background question accommodated: "Who did Gina see at the supermarket?"

(71) \# By the way, MIRANDA .

I propose that, in Full Conditionals like (67a), the Focus on glasses is fine because there are several readings involving Focus projection and accommodation of the appropriate question that do not give rise to any odd presupposition, as in (72)-(74).

(72) a. Background Question: What do you always take to the beach?

b. If I take something to read, I always take [my GLAsses]

(73) a. Background Question: What habit(s) do you have when you take something to read?

b. If I take something to read, I always [take my GLAsses] $]_{\mathrm{F}}$.

(74) a. Background Question: What habit(s) do you have when you go to the beach?

b. [If I take something to read, I always take my GLAsses] $]_{\mathrm{F}}$.

In Reduced Conditionals, instead, Focus cannot project and, furthermore, the Felicity Condition of "free" Focus has to be met via the antecedent-clause from which the elided material is recovered, i.e., the protasis of the Conditional (see sections 3.1 and 3.2). Hence, (67b) carries an odd presupposition because the only way to satisfy the Focus Felicity Condition leads to such presupposition.

Let us examine a further prediction. Full Conditionals with Focus stress on a given constituent have, of course, the option not to project Focus and the option to fulfill the Felicity Condition via the protasis of the conditional. In that case, my analysis predicts they will have the same characteristics (i)-(iv) as RCs. According to most of the 
speakers that I consulted, this prediction is borne out: (75)-(76) have a reading ((75a)(76a)) that displays the exhaustiveness effect. (Note that the exhaustive reading does not entail the non-exhaustive reading in these downward-entailing contexts. Hence, the exhaustive reading is not a subcase of the non-exhaustive one. The two readings have to be generated independently of each other, which I do by positing different levels of Focus marking.) ${ }^{11}$

(75) Hans glaubt nicht, dass, (immer) wenn ich was zum trinken bestelle, Hans believes not, that, (always) if I something to drink order ich BIER bestelle.

I BEER order

"Hans doesn't believe that, if I order something to drink, I order BEER."

a. "Hans doesn't believe that all I order is beer (he may believe that I always order beer plus some other drink)".

(76) Wenn Du, (immer) wenn Du was bestellst, BIER bestellst, wird Ulrike sauer sein. If you (always) if you something order, BEER order, will Ulrike upset be "If , whenever you order something, you order BEER, Ulrike will be upset."

a. "Ulrike will be upset if all you order is beer (but she may be happy as long as you always order beer plus some other drink)."

In conclusion, readings with the characteristics (i)-(iv) arise in Reduced Conditionals as well as in Full Conditionals due to an exhaustive narrow Focus that checks its Felicity Conditions with the protasis of the conditional. Full Conditionals have, furthermore, other readings due to their ease to accommodate the background question and their ability to project Focus.

\section{Concluding Remarks}

Four characteristics of Reduced Conditionals have been explained within a Focusbased approach to ellipsis. The restriction on correlates, the presupposition effect, the exhaustiveness effect, and the definiteness effect follow as a by-product of the interaction between free, exhaustive Focus (as in Q/A pairs) and the general semantics of Conditionals. Further data problematic for previous accounts are also covered by the proposed Focus analysis. Hence, there is no need to stipulate different LF representations for a Reduced Conditional and its full counterpart.

However, some issues still remain open. I will briefly mention two.

First, some effects found in RCs -indefiniteness effect and exhaustiveness effect-are also found in adverbial quantification with Topic/Focus structures (von Fintel 1994:63-5). I leave for future research how the two phenomena can be merged.

Second, my analysis would expect the remnant(s) in the $\mathrm{RC}$ to be able to have contrastive Focus with respect to their correlates in the protasis. That is possible in the full version (77a), but not in the reduced (77b). Future research will have to answer why.

a. Wenn der Tobi die Simone besucht, dann besucht der JENS die CLAUDI

If the Tobi the Simone visits, then visits the JENS the CLAUDI.

"Whenever Tobi visits Simone, JENS visits CLAUDI." 


\section{b. * Wenn der Tobi die Simone besucht, dann $\boldsymbol{\Delta}$ der JENS die CLAUDI. If the Tobi the Simone visits, then $\boldsymbol{\Delta}$ the JENS the CLAUDI "If Tobi visits Simone, then JENS $\Delta$ CLAUDI."}

\section{Endnotes}

* I am grateful to I. Heim, A. Kratzer and B. Schwarz for their helpful comments. This paper has also benefited from the audiences at ZAS/Berlin, University of Delaware, MIT, Philadelphia Semantics Society and SALT X. Many thanks to my informants, specially to $M$. Kappus for his many judgments and valuable observations.

${ }^{1}$ The English cleft construction is often an adequate translation of the German ellipsis clause, but not always. I will give only the neutral translation in the rest of the paper.

${ }^{2}$ Sluicing presents some properties that do resemble, to some extent, some of these characteristics. See Romero (1998) for a Focus-based approach to Sluicing.

${ }^{3}$ The definiteness effect is only discussed in Schwarz (1996), but the analysis in Schwarz $(1998,2000)$ can cover it.

${ }^{4}$ This is not the case in mention-one readings of questions. See also footnote 7.

${ }^{5}$ This derivation of the exhaustivity implicature is inspired -though not completely faithful to it - by the discussion in von Fintel-Heim (1999).

${ }^{6}$ The index 7 -free variable-contextually restricts ADV. (39) combines von Fintel's (1994) general semantics for adverbs of quantification (pp. 17ff) with his more elaborate semantics for conditionals (p. 87). The minimality of the second situation that von Fintel uses for adverbs of quantification with Focus (p. 64) is excluded.

${ }^{7}$ We will see that this exhaustivity implicature in RCs is not easy to cancel, as it isn't in $\mathrm{Q}$ (uestion)/A(nswer) pairs either (see (i)). Also, note that, when relevance fails, the exhaustivity implicature does not arise and we obtain "mention-one" readings both in $\mathrm{Q} / \mathrm{A}$ pairs and in RCs, as in (ii)-(iii).

(i) Q: Who called this morning?

A: \# PETER (with falling pitch accent). And Marga called too.

(ii) Q: Where can I buy Spanish ham in Philadelphia? A: At Sarcone's.

(iii) Wenn man (überhaupt) irgendwo spanischen Schinken kaufen kann, If one ( at all) somewhere Spanish ham buy can dann $\Delta \quad$ (auf jeden Fall) bei Sarcone's. then (in every case / definitely) at Sarcone's.

"If one can buy Spanish ham somewhere, then definitely at Sarcone's."

8 The first alternative -"accompanied by Simone and possibly others"- corresponds to the meaning of the constituent mit Simone "with Simone" itself. In order for the truth conditions in (55) to come out correct, we need to exclude alternatives that would overlap with each other. E.g, we need to exclude "accompanied by Simone only" and "accompanied by Claudi and possibly others". Cf. Simons (1998) for a similar ban against overlapping alternatives.

${ }^{9}$ See Rooth (1992a) and the discussion in Fintel (1994:71) on the semantics of also/too. ${ }^{10}$ As noted above, removing the pitch accent from UND "AND" makes the sentence very marginal. Since part of the remnant material has to bear Focus stress, we have, in principle, the three following possibilities:

a beer $[\mathrm{AND}]_{\mathrm{F}}$ an ouzo 
(ii) a beer [and an OUzo $]_{\mathrm{F}}$

(iii) $\quad[\text { a beer and an OUzo }]_{F}$

Possibility (i) is the one that makes the sentence acceptable. Possibility (ii) may involve defective Focus projection; the meaning it would convey is perfectly sensible, but it is usually expressed by [also an $O U z o]_{\mathrm{F}}$. Possibility (iii) violates Avoid Focus, a ban against having more or larger focused marked constituents than needed for the question I answer match (Schwarzschild 1997).

${ }^{11}$ I do not know how the exhaustive reading of the Full Conditionals (75)-(76) would be derived in Schwarz' system. I assume one could keep his LF (12i) and use different matching relations for the exhaustive (identity relation) and non-exhaustive readings (e.g., the relation of occurring on the same day). However, this still would leave unexplained why the identity matching relation correlates with Focus stress.

\section{References}

von Fintel, K. 1994. Restrictions on Quantifier Domains. Amherst: GLSA. von Fintel, K., and I. Heim. 1999. Pragmatics in Linguistic Theory. MIT lecture notes. Fox, D. 1995. Economy and Scope. Natural Language Semantics.

Hamblin, C. 1973. Questions in Montague English. Foundations of Language 10. Heim, I. 1982. The Semantics of Definite and Indefinite Noun Phrases. Amherst: GLSA. Johnson, K. 1996. Gapping. UMass ms.

Karttunen, L. 1977. Syntax and Semantics of Questions. $L \& P 1$.

Kratzer, A. 1989. An Investigation of the Lumps of Thought. $L \& P 12$.

Kratzer, A. 1998. Scope or Pseudoscope? Are there Wide-Scope Indefinites? In: S. Rothstein (ed.), Events and Grammar. Dordrecht: Kluwer.

Merchant, J. 1999. The syntax of silence: Sluicing, islands, and identity in ellipsis. UCSC Ph. D. Diss.

Portner, P. 1992. Situation Theory and the Semantics of Propositioanl Expressions. Amherst: GLSA.

Romero, M. 1998. Focus and Reconstruction Effects in wh-phrases. UMass Ph.D. Diss.

Rooth, M. 1985. Association with Focus. Amherst: GLSA.

Rooth, M. 1992a. A Theory of Focus Interpretation. Natural Language Semantics 1.

Rooth, M. 1992b. Ellipsis Redundancy and Reduction Redundancy. In S. Berman and A. Hestvik (eds.), Proceedings of the Stuttgart Ellipsis Workshop. Heidelberg: IBM.

Sag, I. 1976. Deletion and Logical Form. Ph. D. Diss, MIT.

Schwarz, B. 1996. The Semantics of Reduced Conditionals in German. UMass talk.

Schwarz, B. 1998. Reduced Conditional in German: Event Quantification and Definiteness. Natural Language Semantics.

Schwarz, B. 2000. Topics on Ellipsis. Amherst: GLSA.

Schwarzschild, R. 1997. Givennenss and Optimal Focus. Ms. Rutgers University.

Simons, M. 1998. On Disjunction. Ithaca: CLC Publications.

Tancredi, C. 1992. Deletion, Deaccenting and Presupposition. MIT Diss.

Tomioka. S. 1995. Focus restricts scope: Quantifier in VP-Ellipsis. In Proceedings of SALT V.

Zucchi, A. 1989. The language of Propositions and Events. Amherst: GLSA. 